\title{
EDIÇÃO COM USO DO EDICTOR DE MANUSCRITOS BAIANOS OITOCENTISTAS: ATAS, CARTAS E PROCURAÇÕES
}

\author{
Emília dos Santos Carneiro'; Mariana Fagundes de Oliveira Lacerda ${ }^{2}$ \\ 1. Bolsista PIBIC/CNPq, Graduando em Licenciatura em Letras Vernáculas, Universidade Estadual de Feira de \\ Santana, e-mail: emiliacarneiro.16@hotmail.cm \\ 2. Mariana Fagundes de Oliveira Lacerda, Departamento de Letras e Artes, Universidade Estadual de Feira de \\ Santana, e-mail: marianafag@gmail.com
}

PALAVRAS-CHAVE: eDictor; Manuscritos baianos; Edição Eletrônica.

\section{INTRODUÇÃO}

As concepções históricas da língua retomaram ao foco das pesquisas linguísticas no final do século $\mathrm{XX}$, junto com o advento das tecnologias, as quais expandiram os recursos para a edição de textos, documento essencial para as pesquisas históricas. Entretanto, também fizeram surgir a necessidade de ampliação de um corpus linguístico para fundamentar uma pesquisa científica. É dentro das perspectivas das Humanidades Digitais e de seu congraçamento com a filologia que surge a possibilidade de responder a exigências da constituição de um corpus linguístico: entre outras, a preservação do material original e a fidelidade ao texto primário (PAIXÃO DE SOUSA, 2009), através da criação de ferramentas computacionais, como o eDictor.

\section{MATERIAL E MÉTODOS OU METODOLOGIA (ou equivalente)}

O programa utilizado para realizar as edições eletrônicas foi o eDictor, uma ferramenta computacional, criado por Paixão de Sousa, Kepler e Faria (2009), com sistema de anotação de edição em XML que permite resguardar as informações filológicas fundamentais dos textos ao mesmo tempo em que os torna aptos para o processamento automático.

O eDictor foi utilizado para realizar as edições em XML de atas, cartas e procurações, manuscritos baianos do século XIX, do Arquivo Municipal de Feira de Santana, editados diplomaticamente por Santana (2007). As edições seguem o padrão utilizado no CE-DOHS (Corpus Eletrônico de Documentos Históricos do Sertão), o qual, por sua vez, é vinculado ao Projeto Tycho Brahe, da Unicamp.

\section{RESULTADOS E/OU DISCUSSÃO (ou Análise e discussão dos resultados)}

As edições eletrônicas, segundo Paixão de Sousa (2010), respondem a uma série de questões relevantes para o estudo das mudanças da língua com o passar do tempo. A preservação dos textos originais, documentos em grande maioria fragilizados, em virtude da passagem do tempo e do pouco ou nenhum cuidado com seu manuseio é uma das preocupações de filólogos, historiadores e linguistas. Junto à conservação do material escrito, há uma outra necessidade, principalmente dos estudos linguísticos: a garantia da fidelidade com o material original para conseguir dados precisos que influenciam nos resultados das pesquisas.

Apesar de já existirem, há muito tempo, formas de preservarem os textos e a possibilidade de garantir a maior fidelidade possível, segundo Cambraia (2005), como 
as edições diplomáticas e semidiplomáticas, o avanço dos estudos linguísticos e a união com as Humanidades Digitais geraram uma outra necessidade: para acontecer o processamento automático dos textos é preciso que o material seja preparado para tal atividade, com um grau de interferência mais elevado do que o realizado em edições conservadoras tradicionais.

$\mathrm{O}$ eDictor foi criado, entre outras funções, para responder tais carências. $\mathrm{O}$ programa referido é uma ferramenta computacional, criado por Paixão de Sousa, Kepler e Faria (2009), com sistema de anotação de edição em XML que permite resguardar as informações filológicas fundamentais dos textos ao mesmo tempo em que os torna aptos para o processamento automático, incluindo etiquetagem morfológica e anotações sintáticas, as quais facilitam a seleção de dados.

A preservação e fidelidade do texto original ocorre da seguinte maneira: os textos editados diplomaticamente (ou semidiplomaticamente) são preparados para a edição XML, a qual envolve, entre outros processos, a etiquetagem: tudo que é feito durante a edição é devidamente marcado.

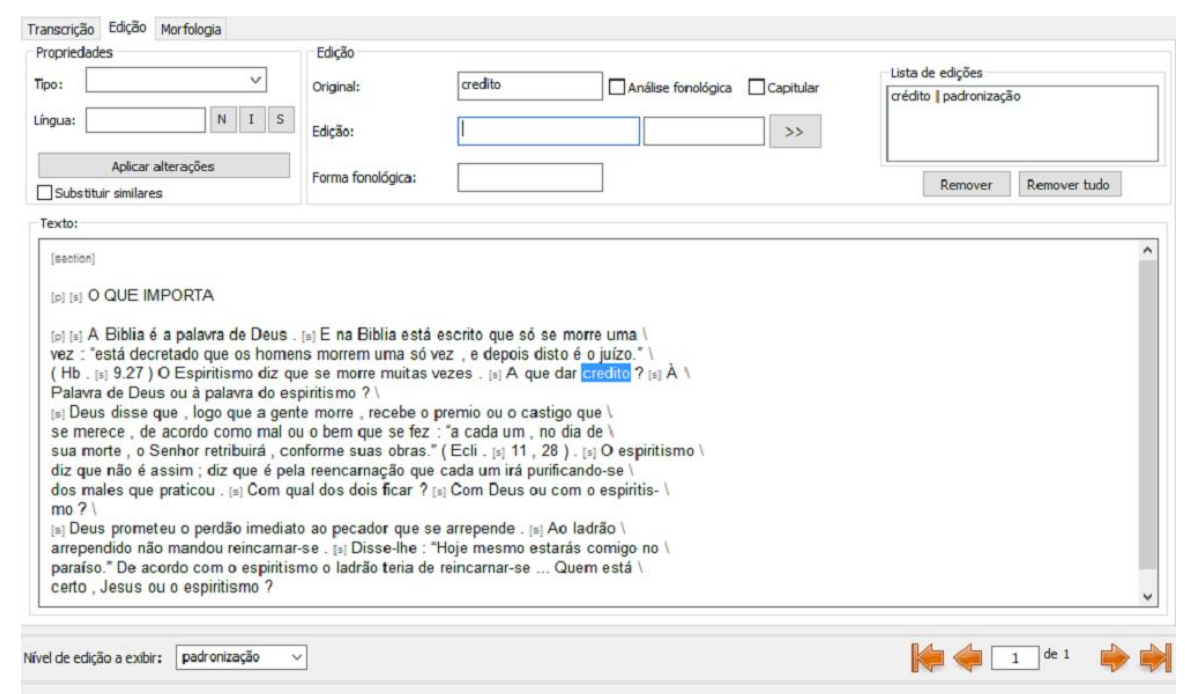

Figura 01

Conforme figura 01, durante a edição é possível visualizar a palavra original e os processos realizados, na lista de edições, os quais dependem do tipo de edição feito. As edições modernizadas, por exemplo, garantem uma leitura facilitada por estudiosos de áreas diversas da Linguística e, para tal, é preciso padronizar as palavras escritas de forma diferente no século XIX.

Ao término da edição e com a divulgação online, é possível visualizar a edição modernizada junto com o texto original: 


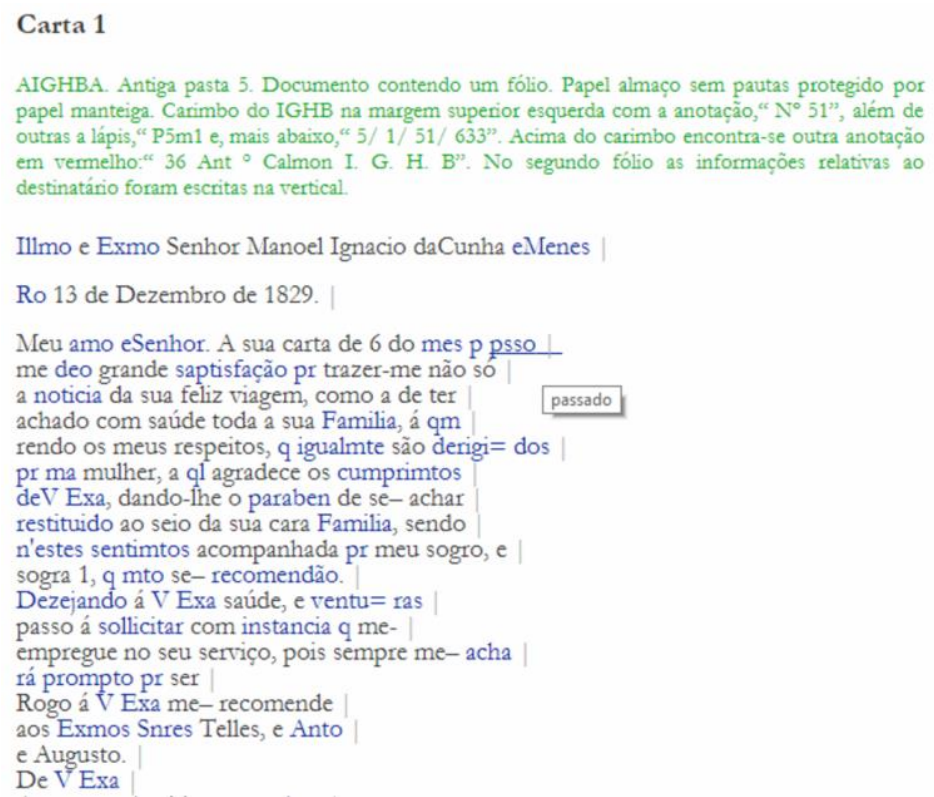

Figura 02

Os manuscritos baianos do Arquivo Municipal de Feira de Santana, editados diplomaticamente por Santana e publicadas por Queiroz (2004), e, editados eletronicamente como objetivo deste trabalho, constituem um corpus relevante para investigações sobre a constituição do português no interior da Bahia e as mudanças ocorridas ao longo do tempo. As atas, cartas e procurações, escritas no século XIX, além de preservar um importante material sobre a história da cidade, oferece também dados para pesquisas lexicais, morfológicas, sintáticas, dentre tantas outras áreas de estudo da linguagem.

A análise cuidadosa dos gêneros textuais, contextualizando-os ao século em que foi escrito, permitiu a realização das edições eletrônicas atendendo aos critérios do CEDOHS e às particularidades de cada documento. A preparação das edições XML possibilita, no futuro, a análise automática e o avanço na construção de corpus para pesquisas linguísticas.

\section{CONSIDERAÇÕES FINAIS (ou Conclusão)}

Os documentos do século XIX podem ser estudados sobre diferentes vias, cada qual com sua funcionalidade. Há a possibilidade de estudar o passado do português, concentrando-se nele, e também o estudo do passado para explicar a língua atual, sendo, por isso, relevante a edição de tal material como fornecimento de dados a pesquisas de diversas áreas da linguística.

A realização da edição em XML das atas, cartas e procurações do século XIX amplia o banco de dados do CE-DOHS, agregando, junto aos corpora já existentes, gêneros textuais diversos e escritos em âmbitos formais. Os textos editados em XML possibilitam uma preparação futura para a anotação sintática, o que, junto a outros programas computacionais, facilita a busca de dados específicos para constituição de corpus. Além disso, a divulgação do texto editado, junto ao texto original, viabilidade oferecida pelo eDictor, facilita também as pesquisas históricas, geográficas, jurídicas, entre tantas outras áreas beneficiadas 


\section{REFERÊNCIAS}

Paixão de Sousa, M. C.; Kepler, F. N.; Faria, P. E-dictor: Novas perspectivas na codificação e edição de corpora de textos históricos. In: VIII Encontro de Linguística de Corpus, 2009, Rio de Janeiro. Resumos, 2009.

Paixão de Sousa, M. C.; Kepler, F. N.; Faria, P. E-dictor: Novas perspectivas na codificação e edição de corpora de textos históricos. In: VIII Encontro de Linguística de Corpus, 2009, Rio de Janeiro. Resumos, 2009.

Paixão de Sousa, M. C.; Kepler, F. N.; Faria, P. P. F. E-Dictor: Novas perspectivas na codificação e edição de corpora de textos históricos. In: Tania Shepherd; Tony Berber Sardinha; Marcia Veirano Pinto. (Org.). Caminhos da linguística de corpus. Campinas: Mercado de Letras, 2010 